Bài báo khoa học

\title{
Thử nghiệm đánh giá khách quan chất lượng dự báo nhiệt độ bằng phần mềm trong nghiệp vụ dự báo
}

\author{
Lê Đại Thắng ${ }^{1 *}$, Nguyễn Viết Lành ${ }^{2}$ \\ ${ }^{1}$ Trung tâm Thông tin và Dữ liệu khí tượng thủy văn; ledaithang.73@gmail.com \\ ${ }^{2}$ Trường Đại học Tài nguyên và Môi trường Hà Nội; nvlanh@hunre.edu.vn \\ * Tác giả liên hệ: ledaithang.73@gmail.com; Tel: +84-989066595
}

Ban Biên tập nhận bài: 5/8/2020; Ngày phản biện xong: 1/9/2020; Ngày đăng: 25/9/2020

Tóm tắt: Trong dự báo thời tiết điểm hiện nay tại Việt Nam, để tiến hành thực hiện bài toán đánh giá chất lượng dự báo các yếu tố dự báo sẽ được phân chia thành hai loại: biến theo pha (phân nhóm) và biến liên tục, đối với mỗi loại biến sẽ yêu cầu tính toán các chỉ số sai số dự báo và áp dụng kỹ thuật phân tích khác nhau. Trong phạm vi nghiên cứu này, Chúng tôi sử dụng phương pháp chuẩn đánh giá chất lượng dự báo bằng sự kết hợp của hai kỹ thuật phân tích toán đồ tụ điểm và phân tích tham số, áp dụng đánh giá chất lượng dự báo yếu tố nhiệt độ cực trị ngày (biến liên tục) trong tháng 4 năm 2020 cho điểm Hà Nội bằng phần mềm tự động đánh giá khách quan chất lượng dự báo. Kết quả nghiên cứu cho thấy sai số dự báo nhiệt độ tối cao lớn hơn sai số dự báo nhiệt độ tối thấp và giá trị nhiệt độ cực trị ở các hạn dự báo đa phần thường dự báo thấp hơn so với giá trị quan trắc, ngoài ra còn rất nhiều thông tin khác rất hữu ích về chất lượng dự báo, kết quả nghiên cứu sẽ trợ giúp Dự báo viên và người quản lý kịp thời điều chỉnh dự báo và có kế hoạch nghiên cứu, cải tiến và phát triển nâng cao trình độ dự báo trong tương lai.

Từ khóa: Dự báo điểm; Đánh giá chất lượng dự báo; Phương pháp chuẩn.

\section{Mở đầu}

Tổ chức khí tượng thế giới (WMO) đã phát hành tài liệu về các phương pháp đánh giá chất lượng dự báo, các phương pháp đánh giá chất lượng dự báo được nêu ra chủ yếu là thống kê với các tham số. Cần lưu ý là trong đánh giá chất lượng dự báo, WMO rất coi trọng về phương pháp, WMO đã tổ chức tới 7 Hội thảo quốc tế về phương pháp đánh giá dự báo, Hội thảo gần đây nhất được tổ chức vào tháng 5/2017 tại Đức với chủ đề: Phương pháp đánh giá dự báo theo không gian và thời gian $[1,3]$. Có nhiều kỹ thuật dùng để đánh giá chất lượng dự báo, kỹ thuật được sử dụng nhiều là lý thuyết [2-4], theo đó có 3 vấn đề cần đánh giá: (1) Độ chính xác: được tính bằng nhiều công thức phức tạp cho kết quả độ chính xác dự báo được so sánh bởi tần suất phân bố khác nhau giữa giá trị dự báo và quan trắc; (2) Kỹ năng: được đánh giá bởi giá các thông tin được thêm vào trong quá trình dự báo; (3) Độ tin cậy: cho biết sự quan hệ chặt chẽ giữa giá dự báo với thực tế, ý nghĩa của nó cho biết phương pháp dự báo có "độ tin cậy" được đảm bảo hay không. Với ba nội dung nêu trên, nghiên cứu lựa chọn yếu tố dự báo là nhiệt độ cực trị để làm đối tượng nghiên cứu ứng dụng phương pháp chuẩn đánh giá chất lượng dự báo.

\section{Số liệu và phương pháp nghiên cứu}

\subsection{Nguồn số liệu đầu vào}


Nguồn số liệu đầu vào là số liệu dự báo nhiệt độ cực trị ngày tháng 4 năm 2020 của Trung tâm Dự báo khí tượng thủy văn (KTTV) quốc gia, dự báo cho 63 điểm đặc trưng của 63 tỉnh/thành phố của Việt Nam, với hạn dự báo từ 1 đến 10 ngày và số liệu quan trắc nhiệt độ cực trị tương ứng với các vị trí của điểm dự báo của 63 trạm khí tượng để so sánh và tính toán các chỉ số sai số của dự báo của yếu tố nhiệt độ tối cao $(\mathrm{Tx})$ và nhiệt độ tối thấp ngày $(\mathrm{Tn})$.

\subsection{Phuơng pháp chuẩn đánh giá chất lượng dụ báo}

Phương pháp đánh giá chất lượng cổ điển là phương pháp thị giác (eyeball), cách phổ biến là trình bày dữ liệu dưới dạng biểu đồ đường và điểm theo thời gian, sau đó xem xét giá trị dự báo và quan trắc gần hay xa nhau và sử dụng phán đoán của con người để phân tích các sai số dự báo.

Phần mềm tự động tính toán các chỉ số sai số dự báo: Bias, ME, MAE, MSE, RMSE, PC [1].

\section{Kết quả và thảo luận}

Sau khi Hệ thống thu nhận đầy đủ số liệu dự báo và quan trắc, phần mềm dựa trên cơ sở dữ liệu đã có sẽ tự động tính toán thống kê các chỉ số sai số dự báo nhiệt độ cực trị ngày và hiển thị kết quả chất lượng dự báo của từng điểm riêng biệt với hạn dự báo từ 1 đến 10 ngày tại 63 điểm dự báo. Kết quả đánh giá chất lượng dự báo nhiệt độ cực trị ngày của các hạn dự báo từ 1 đến 10 ngày trong tháng 4/2020 cho điểm Hà Nội được dẫn ra trong Hình 1.

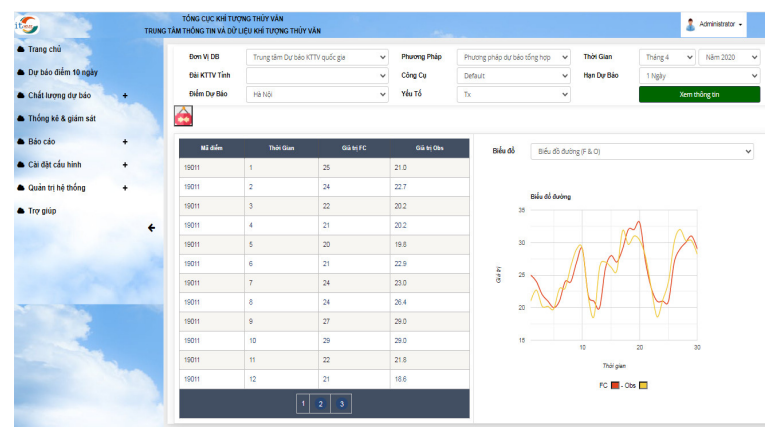

(a)

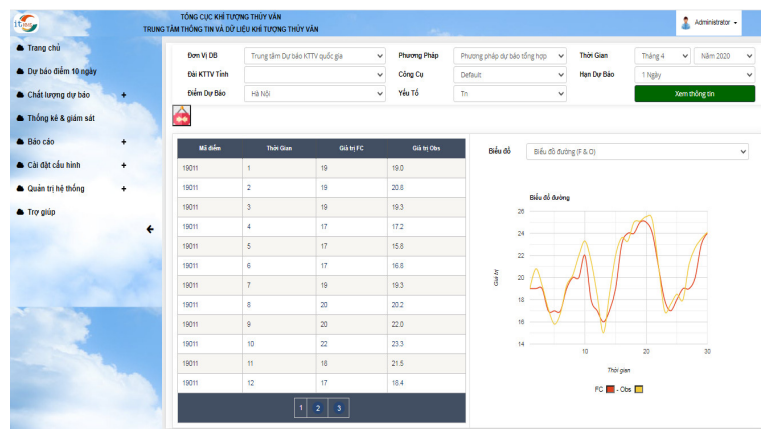

(b)

Hình 1. Kết quả dự báo và quan trắc Tx (a) và Tn (b) tháng 4/2020 của điểm Hà Nội.

Kết quả hiển thị trên phần mềm (hình $1 \mathrm{a}$ và $1 \mathrm{~b}$ ) chia 2 phần: bên trái là bảng dữ liệu gồm: Mã điểm dự báo, Ngày dự báo, Dữ liệu dự báo (Cột: Giá trị FC) và Giá trị quan trắc (Cột: Giá trị $O b s)$, bên phải là các dạng biểu đồ mô tả giá trị dự báo và quan trắc của các ngày trong tháng, có thể xem kết quả của từng hạn dự báo khác nhau.

Kết quả đánh giá chất lượng dự báo có được thông qua việc phân tích biểu đồ và phân tích tham số thống kê sẽ được trình bày dưới đây:

\subsection{Kết quả phân tích biểu đồ}

Kết quả dự báo của các hạn dự báo đối với yếu tố nhiệt độ cực trị các ngày trong tháng 4/2020 được hiển thị bằng ba loại biểu đồ:

- Biểu đồ đường (Hình $2 \mathrm{a}$ ) là biến trình nhiệt độ cực trị: màu đỏ là giá trị nhiệt độ cực trị ngày dự báo, màu vàng là giá trị nhiệt độ cực trị ngày quan trắc;

- Biểu đồ điểm có tọa độ là các giá trị cực trị dự báo và giá trị cực trị quan trắc của các ngày trong tháng 4 (Hình 2b);

- Biểu đồ điểm giá trị sai số dự báo theo thời gian (Hình $2 \mathrm{c}$ ).

Do khuôn khổ của bài báo, chúng tôi chỉ dẫn biểu đồ kết quả dự báo và quan trắc nhiệt cực trị ngày với các thời hạn dự báo: $1,3,5,7$ và 10 ngày. 
Kết quả dự báo nhiệt độ tối cao ngày của 5 hạn dự báo này được trình bày từ Hình 2 đến Hình 6.

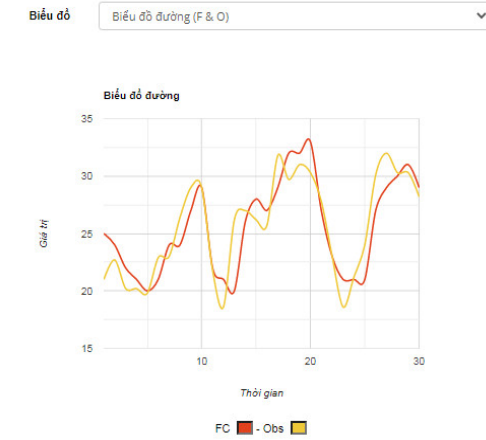

(a) Biểu đồ đường giá trị quan trắc và dự báo

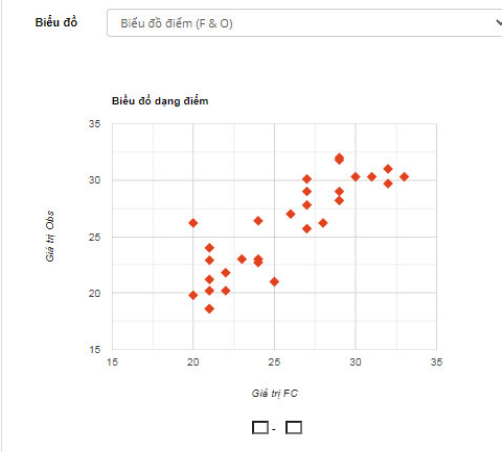

b) Biểu đồ điểm giá trị quan trắc và dự báo

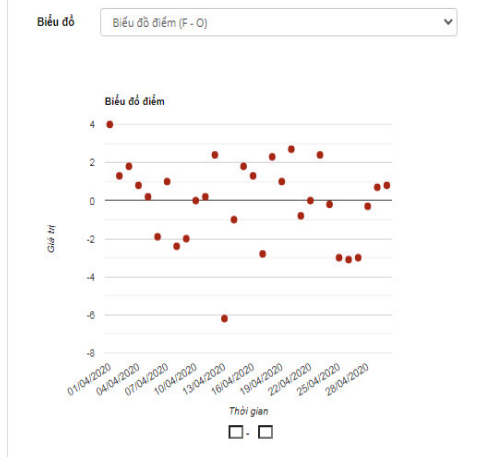

c) Biểu đồ sai số giá trị quan trắc và dự báo

Hình 2. Kết quả dự báo và quan trắc nhiệt độ tối cao ngày, hạn dự báo 1 ngày.

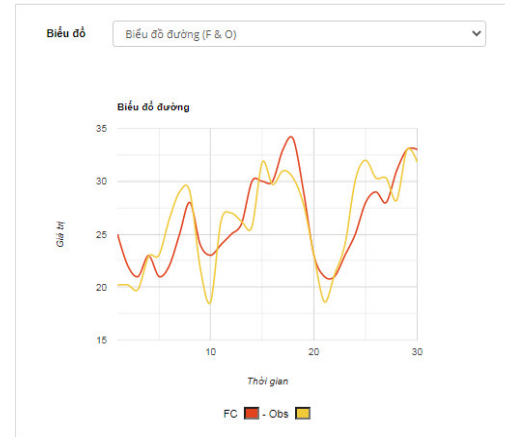

a) Biểu đồ đường giá trị quan trắc và dự báo

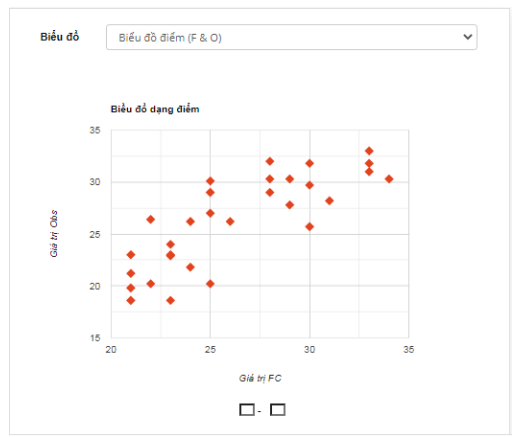

b) Biểu đồ điểm giá trị quan trắc và dự báo

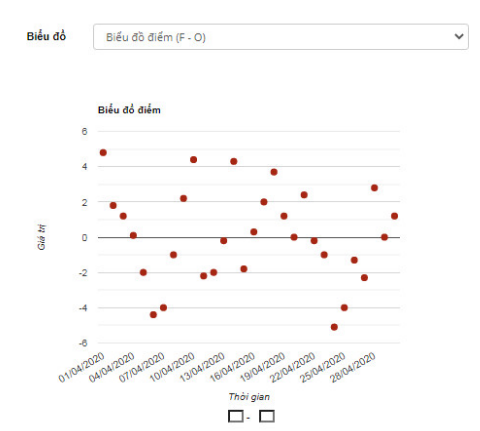

c) Biểu đồ sai số giá trị quan trắc và dự báo

Hình 3. Kết quả dự báo và quan trắc nhiệt độ tối cao ngày, hạn dự báo 3 ngày.

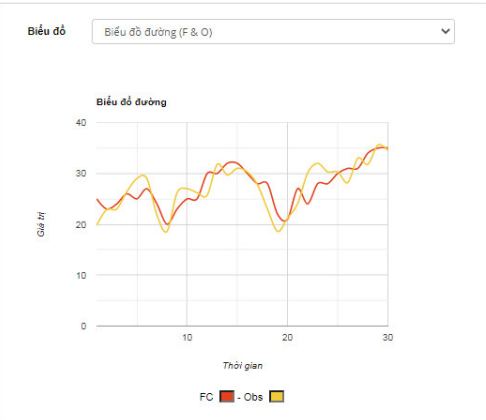

a) Biểu đồ đường giá trị quan trắc và dự báo

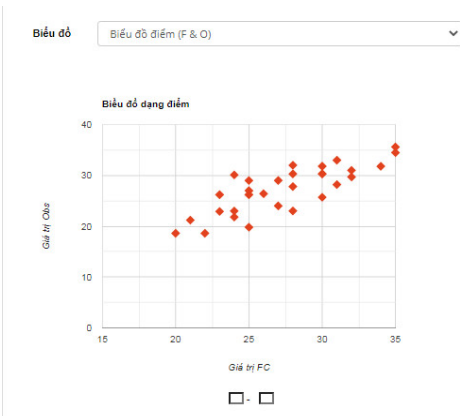

b) Biểu đồ điểm giá trị quan trắc và dự báo

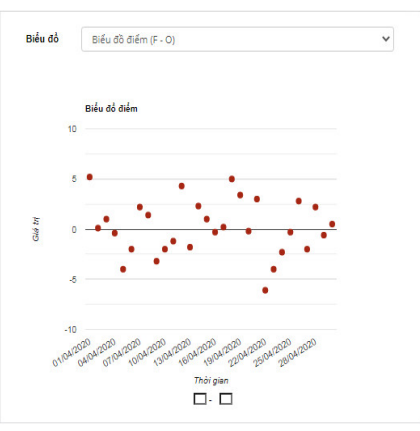

c) Biểu đồ sai số giá trị quan trắc và dự báo

Hình 4. Kết quả dự báo và quan trắc nhiệt độ tối cao ngày, hạn dự báo 5 ngày.

Phân tích trên biểu đồ đường (Hình a) của các hạn dự báo cho thấy, biến trình giá trị nhiệt độ tối cao ngày trong tháng 4 quan trắc được và giá trị nhiệt độ tối cao dự báo tương đối sát, xu thế biến đổi hàng ngày của nhiệt độ tối cao đều được dự báo điều chỉnh kịp thời, điều đó có nghĩa độ tin cậy và ổn định của phương pháp và công cụ dự báo. Riêng hạn dự báo 10 ngày 
(Hình 6a) đã dự báo ngược xu thế: dự báo nhiệt độ tối cao tăng trong khi thực tế giảm, dẫn đến sai số lớn: $12,4^{\circ} \mathrm{C}$ (dự báo $\mathrm{Tx}_{\mathrm{db}}=31,0^{\circ} \mathrm{C}$, quan trắc $\mathrm{Tx}_{\mathrm{obs}}=18,6^{\circ} \mathrm{C}$ ).

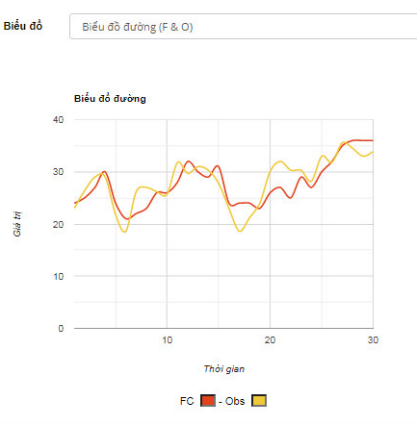

a) Biểu đồ đường giá trị quan trắc và dự báo

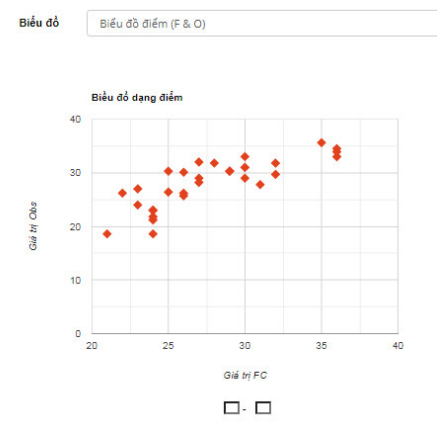

b) Biểu đồ điểm giá trị quan trắc và dự báo

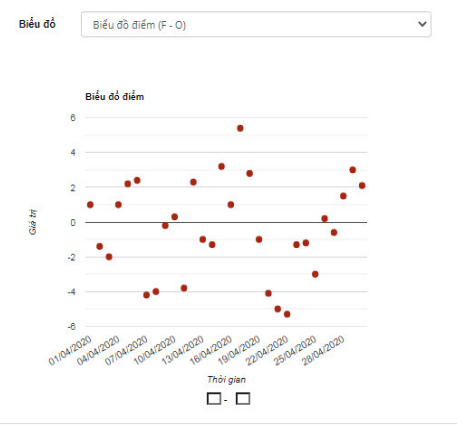

c) Biểu đồ sai số giá trị quan trắc và dự báo

Hình 5. Kết quả dự báo và quan trắc nhiệt độ tối cao ngày, hạn dự báo 7 ngày.

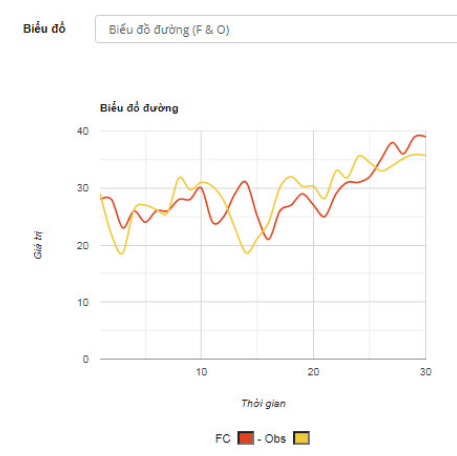

a) Biểu đồ đường giá trị quan trắc và dự báo

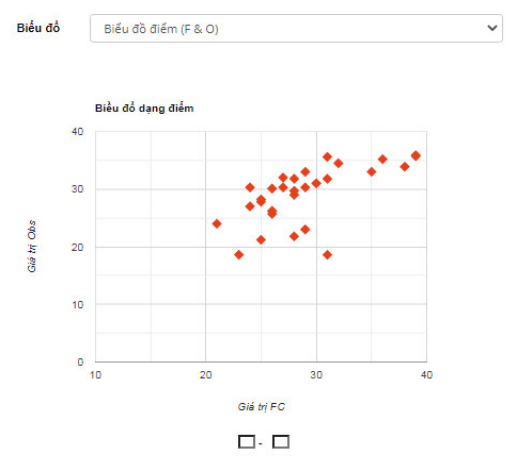

b) Biểu đồ điểm giá trị quan trắc và dự báo

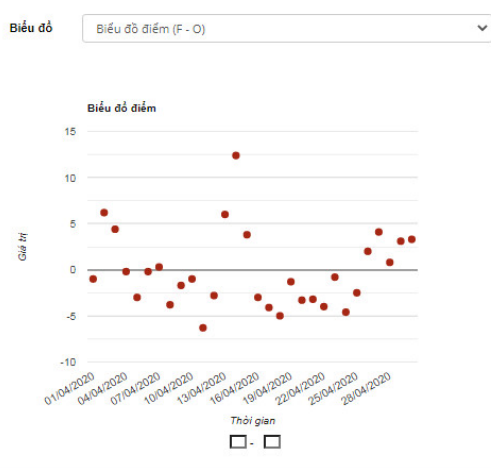

c) Biểu đồ sai số giá trị quan trắc và dự báo

Hình 6. Kết quả dự báo và quan trắc nhiệt độ tối cao ngày, hạn dự báo 10 ngày.

Phân tích trên biểu đồ điểm (b) cho chúng ta thêm thông tin chi tiết hơn về kết quả dự báo: đối với hạn dự báo 1,3 và 10 ngày các điểm có xu thế tập trung trên đường phân giác với hệ số góc tương đương, xấp xỉ bằng nhau, mặc dù sai số các hạn dự báo là khác nhau nhưng cho thấy độ ổn định của dự báo là rất tốt, riêng đối với các hạn dự báo 5 và 7 ngày, độ lệch của dự báo so với quan trắc lớn hơn ở những ngày có nhiệt độ cao.

Phân tích trên biểu đồ điểm sai số dự báo $(\mathrm{c})$ cho thấy phần nhiều giá trị dự báo đều dưới ngưỡng giá trị thực đo $(-)$, mức độ sai số của giá trị dự báo và quan trắc với giá trị dự báo là rất khác nhau tại các hạn dự báo, riêng hạn dự báo 10 ngày có số điểm sai số lệch âm nhiều hơn sai số dương, bên cạnh đó có những điểm nằm cách xa cần được phân tích chuyên sâu để tìm nguyên nhân đúc rút kinh nghiệm dự báo sau này.

Kết quả dự báo nhiệt độ tối thấp ngày của 5 hạn dự báo này được trình bày từ Hình 7 đến Hình 11. Phân tích trên biểu đồ đường (a) của các hạn dự báo cho thấy biến trình giá trị quan trắc của nhiệt độ tối thấp ngày và giá trị nhiệt độ tối thấp dự báo trong tháng 4 là tương đối sát, $x u$ thế biến đổi hàng ngày của nhiệt độ tối thấp ở hầu hết các hạn dự báo đều rất tốt, riêng hạn dự báo 5 và 7 ngày (Hình 9 và 10) có sai số lớn do dự báo ngược xu thế so với thực tế, điều đó cho thấy những ngày này đã có sự đột biến về thời tiết và các hạn dự báo này đã chưa kịp thời dự báo chính xác sự biến động của thời tiết. 


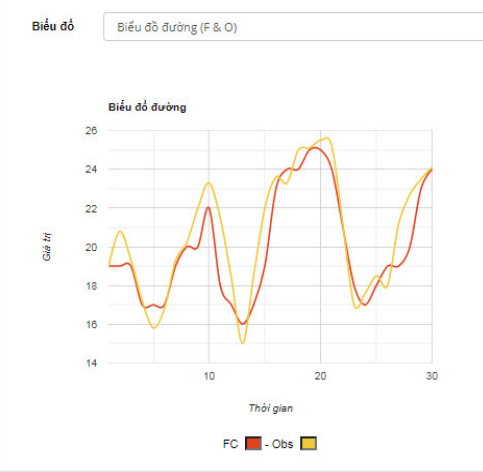

a) Biểu đồ đường giá trị quan trắc và dự báo

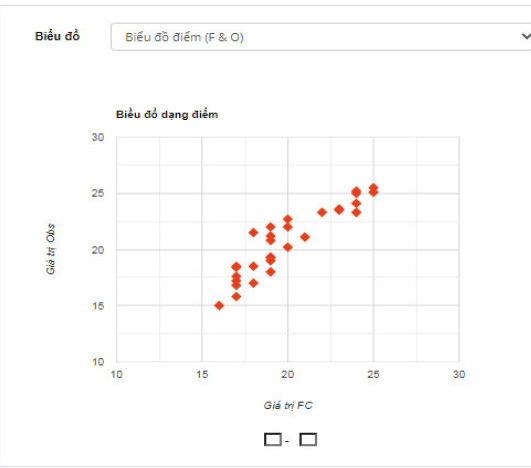

b) Biểu đồ điểm giá trị quan trắc và dự báo

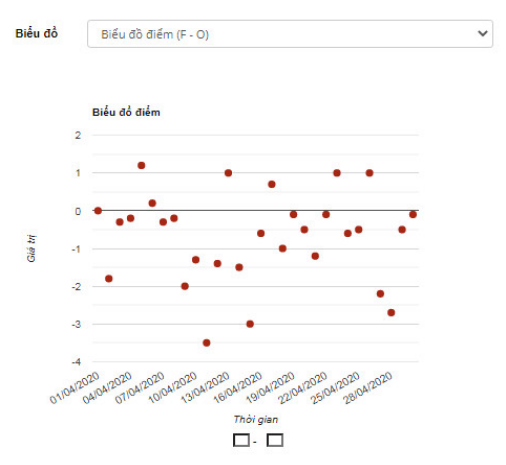

c) Biểu đồ sai số giá trị quan trắc và dự báo

Hình 7. Kết quả dự báo và quan trắc nhiệt độ tối thấp ngày, hạn dự báo 1 ngày.

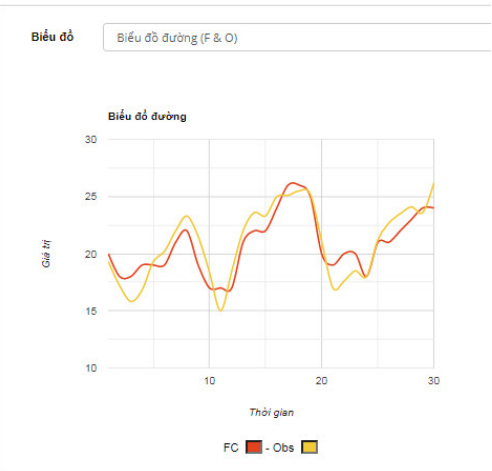

a) Biểu đồ đường giá trị quan trắc và dự báo

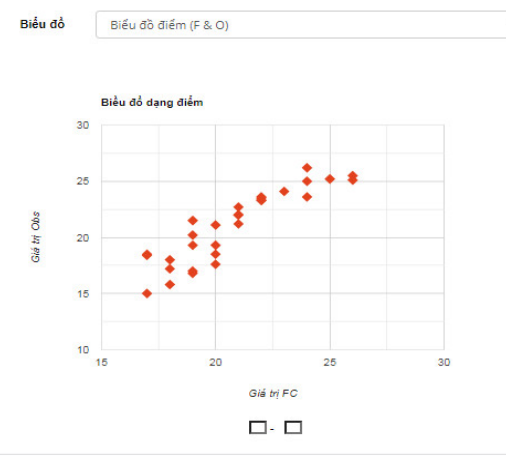

b) Biểu đồ điểm giá trị quan trắc và dự báo

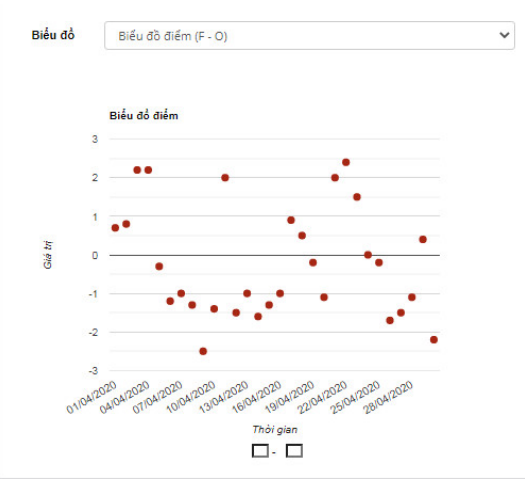

c) Biểu đồ sai số giá trị quan trắc và dự báo

Hình 8. Kết quả dự báo và quan trắc nhiệt độ tối thấp ngày, hạn dự báo 3 ngày.

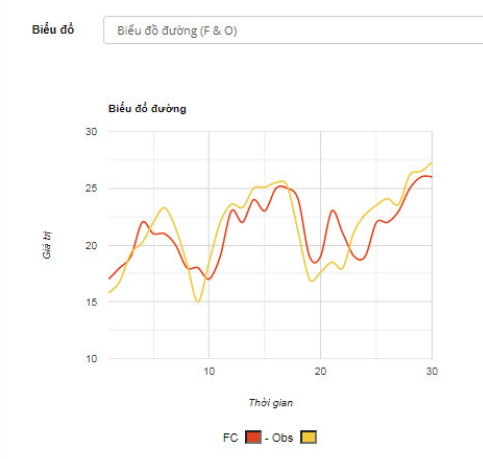

a) Biểu đồ đường giá trị quan trắc và dự báo

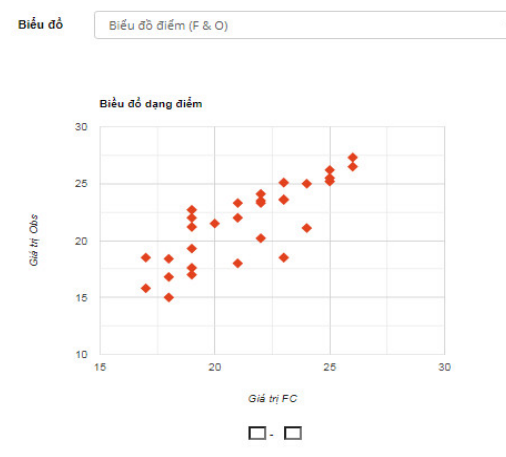

b) Biểu đồ điểm giá trị quan trắc và dự báo

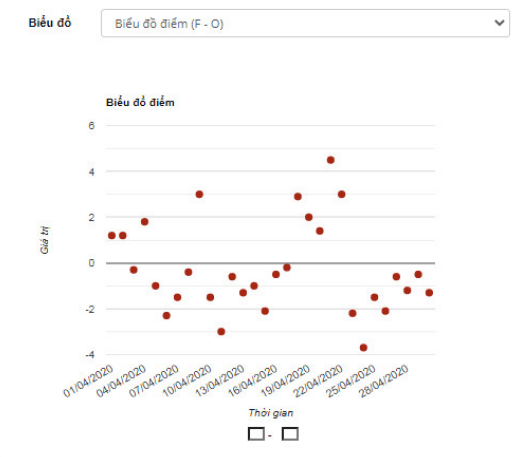

c) Biểu đồ sai số giá trị quan trắc và dự báo

Hình 9. Kết quả dự báo và quan trắc nhiệt độ tối thấp ngày, hạn dự báo 5 ngày.

Phân tích trên biểu đồ điểm (b) cho thấy mức độ tập trung của các điểm chỉ ổn định ở các hạn dự báo 1 và 3 ngày, ngoài ra đối với các hạn dự báo khác (5 và 10 ngày) mức độ phân tán của các điểm là rất rộng, thường xảy ra ở các ngày có nhiệt độ thấp. Điều đó có nghĩa sai số 
dự báo nhiệt độ tối thấp sẽ tương đối cao và đặc biệt cao ở những ngày có nhiệt độ thấp và ổn định và chính xác hơn ở những ngày có nhiệt độ cao.

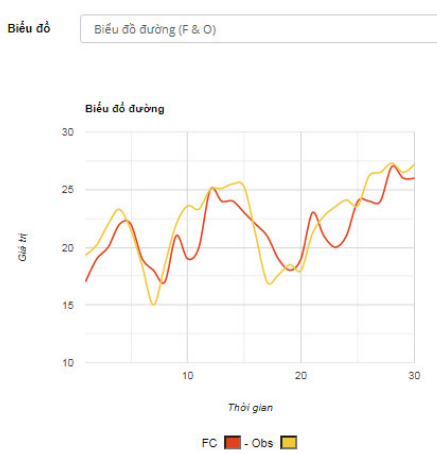

a) Biểu đồ đường giá trị quan trắc và dự báo

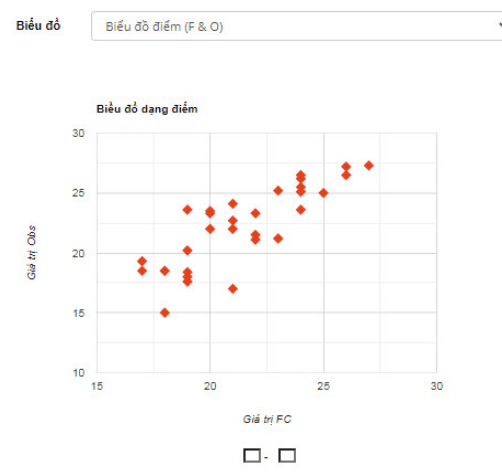

b) Biểu đồ điểm giá trị quan trắc và dự báo

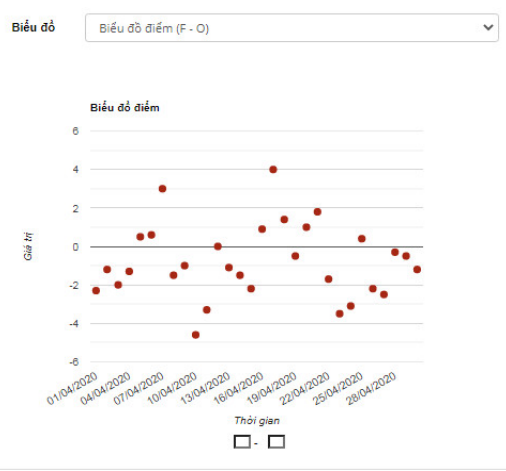

c) Biểu đồ sai số giá trị quan trắc và dự báo

Hình 10. Kết quả dự báo và quan trắc nhiệt độ tối thấp ngày, hạn dự báo 7 ngày.

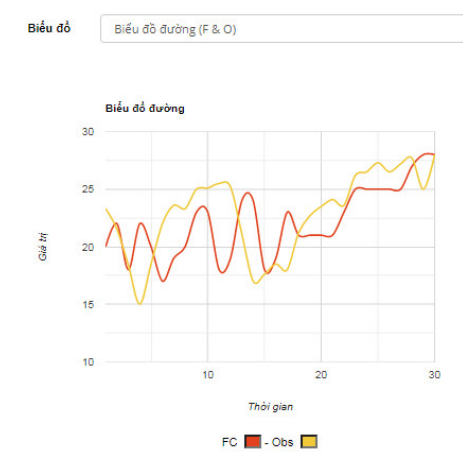

a) Biểu đồ đường giá trị quan trắc và dự báo

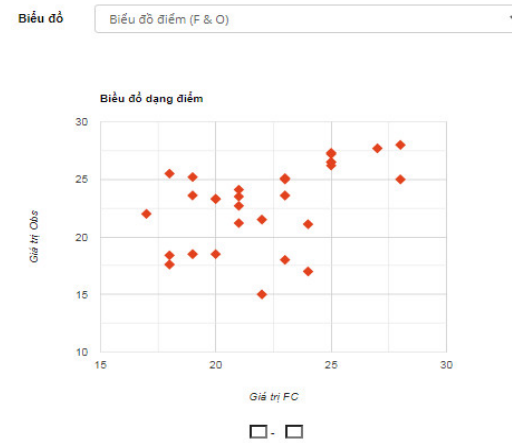

b) Biểu đồ điểm giá trị quan trắc và dự báo

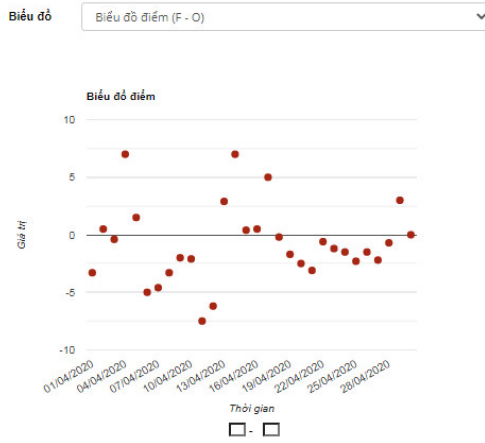

c) Biểu đồ sai số giá trị quan trắc và dự báo

Hình 11. Kết quả dự báo và quan trắc nhiệt độ tối thấp ngày, hạn dự báo 10 ngày.

Phân tích trên biểu đồ điểm sai số dự báo (c) cho thấy cũng giống như dự báo nhiệt độ tối cao ở trên, phần nhiều giá trị dự báo nhiệt độ tối thấp trong tháng 4 đều dưới ngưỡng giá trị thực đo $(-)$, điều này phản ảnh rất rõ trong Hình a khi mà đường biến trình dự báo luôn thấp hơn so với đường biến trình giá trị quan trắc, chúng ta có thể thấy rõ nhất ở Hình $\mathrm{c}$, số điểm nằm dưới hoành độ $(0)$ nhiều hơn số điểm nằm trên trục hoành.

Sử dụng phương pháp phân tích các loại biểu đồ này các dự báo viên sẽ phân tích đánh giá sai số dự báo của phương pháp từ đó sẽ có những điều chỉnh kịp thời để nâng cao chất lượng dự báo nói chung và dự báo nhiệt độ cực trị nói riêng.

\subsection{Kết quả tính toán, phân tích giá trị sai số dụ báo}

Chức năng của phần mềm không những hiển thị dữ liệu dưới dạng biểu đồ mà còn tự động tính toán các chỉ số sai số dự báo đối với các yếu tố dự báo là nhiệt độ tối cao ngày (Hình $12 \mathrm{a}$ ) và nhiệt độ tối thấp ngày (Hình $12 \mathrm{~b}$ ) theo các hạn dự báo khác nhau (từ 1 đến 10 ngày) cho điểm dự báo Hà Nội tháng 4 năm 2020 và hiển thị kết quả trên giao diện của phần mềm.

Kết quả hiển thị trên phần mềm (hình $12 \mathrm{a}-12 \mathrm{~b}$ ) phân chia làm hai phần: Bảng dữ liệu bên trái là dữ liệu các chỉ số sai số của yếu tố dự báo tính toán đượ (dòng thứ nhất), bao gồm các chỉ số Bias, ME, MAE, RMSE, MSE và $\mathrm{PC}$ của các hạn dự báo từ 1 đến 10 ngày (cột 
Ngày); Biểu đồ bên phải là mô tả giá trị các chỉ số đối với các hạn dự báo khác nhau (có 3 loại biểu đồ dùng để mô tả các dữ liệu của từng chỉ số hoặc tất cả các chỉ số đó là Biểu đồ dạng đường, Biểu đồ dạng cột và Biểu đồ dạng điểm).

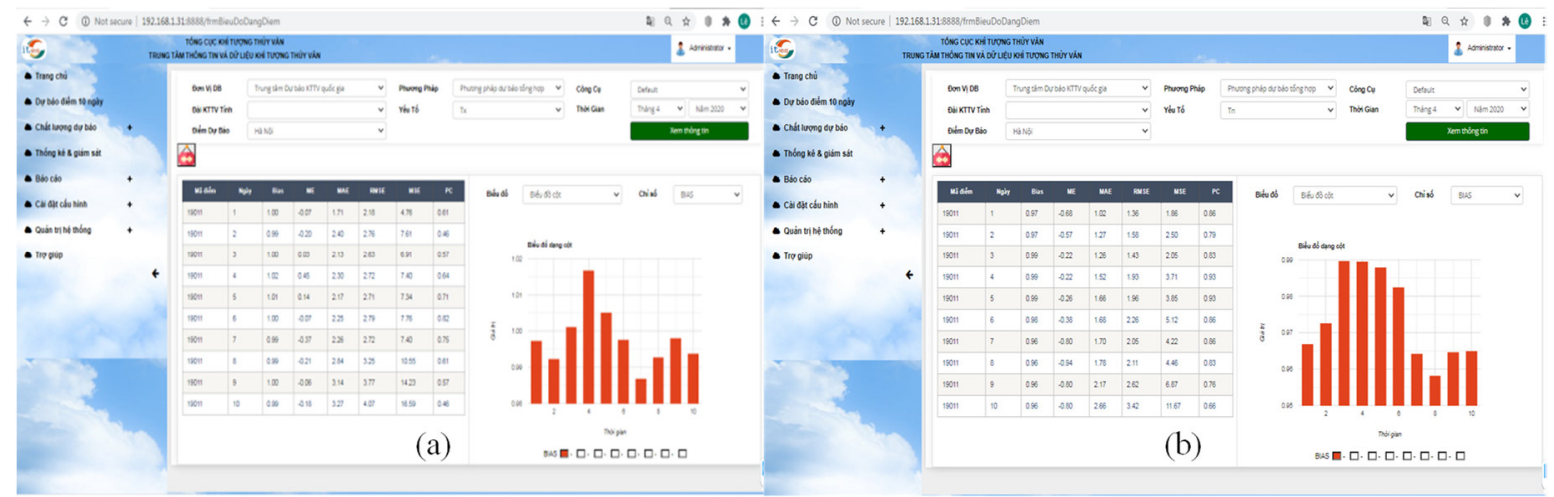

Hình 12. (a) Sai số dự báo nhiệt độ tối cao của các hạn dự báo; (b) Sai số dự báo nhiệt độ tối thấp của các hạn dự báo.

\subsubsection{Kết quả sai số dự báo nhiệt độ tối cao}

- Chỉ số Bias nhận giá trị từ 0,99 đến 1,02 (hình $13 \mathrm{a}$ ), trong đó hầu hết các hạn dự báo độ lệch nhỏ, trong khi đa phần các hạn dự báo có giá trị Bias $<1$ thì hạn dự báo 3,4 và 5 ngày có độ lệch Bias $>1$ cho thấy giá trị dự báo lớn hơn giá trị thực đo, còn lại đa phần các hạn dự báo khác đều dự báo thấp hơn giá trị thực đo. Độ lệch phản ánh mức độ tin cậy của hạn dự báo và giá trị dự báo tốt nhất tại hạn dự báo 3 ngày $(\operatorname{Bias}=1,001)$.

- Chỉ số ME nhận giá trị từ -0,37 đển 0,45 (hình $13 b$ ), trong đó các hạn dự báo 2,3 và 4 ngày có sai số trung bình với giá trị dương $(+)$ trong khi các hạn dự báo còn lại có sai số trung bình với giá trị âm (-), sai số lớn nhất thuộc về hạn dự báo 4 và 7 ngày phản ánh đúng như kết quả phân tích chỉ số Bias ở trên.
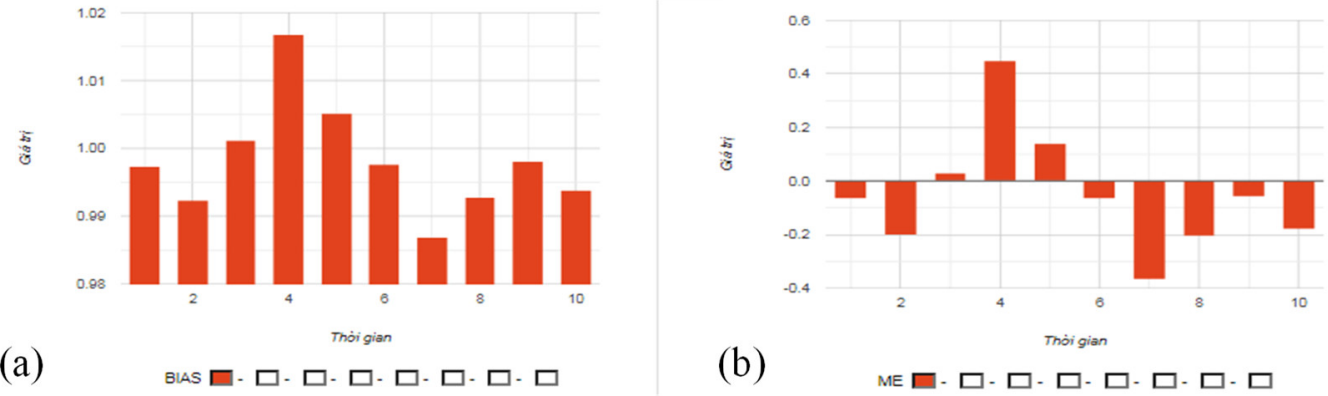

Hình 13. (a) Chỉ số Bias của các hạn dự báo; (b) Chỉ số ME của các hạn dự báo.

- Chỉ số MAE nhận giá trị từ 1,71 đến 3,27 (hình14a), có nghĩa sai số tuyệt đối có xu thế tăng dần theo các hạn dự báo, hạn càng dài sai số càng lớn đúng với quy luật chung nhưng trong trường hợp này có sự bất thường khi sai số của hạn dự báo 5,6 và 7 ngày lại tốt lên phản ánh quan hệ của giá trị dự báo và quan trắc chặt chẽ hơn.

- Chỉ số RMSE nhận giá trị từ 2,18 đến 4,07 (hình 14b), chỉ mức độ sai số trung bình của dự báo các giá trị sai số có xu thế tăng dần theo các hạn dự báo, hạn càng dài sai số càng lớn sai số cũng giống như biểu đồ chỉ số MAE đối với các hạn dự báo.

- Chỉ số MSE nhận giá trị từ 4,76 đến 16,59 (hình 14c), chỉ mức độ sai số trung bình của dự báo các giá trị sai số có xu thế tăng dần theo các hạn dự báo, hạn càng dài sai số càng lớn về bản chất cũng giống như biểu đồ chỉ số RMSE và MAE. 
- Chỉ số PC nhận giá trị từ 0,46 đến 0,81 (hình $14 \mathrm{~d}$ ), chất lượng dự báo tốt nhất tại các hạn dự báo 5,6 và 7 ngày, thấp nhất đối với hạn dự báo 2 và 10 ngày $(0,46)$.

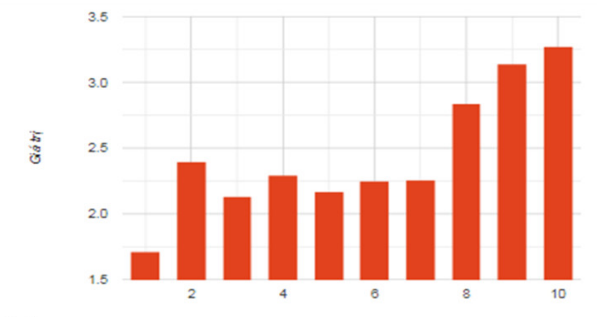

(a)

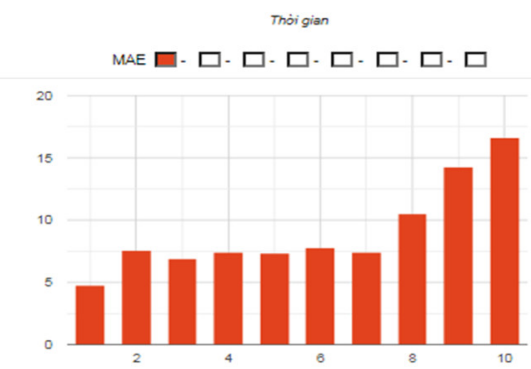

(c)

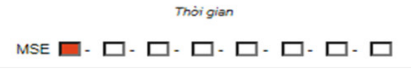

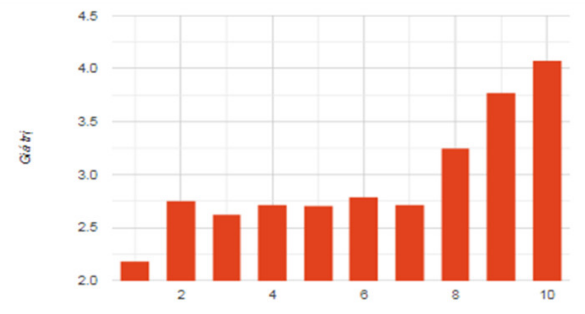

(b)

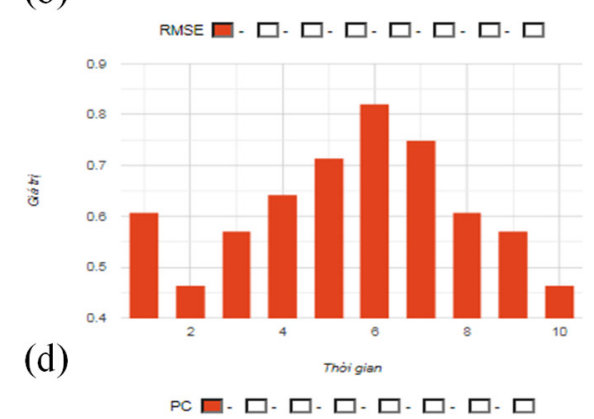

Hình 14. Chỉ số đánh giá của các hạn dự báo: (a) MAE; (b) RMSE; (c) MSE; (d) PC.

\subsubsection{Sai số dự báo nhiệt độ tối thấp}

- Chỉ số Bias nhận giá trị từ 0,96 đến 0,99 (hình 15a), giống như sai số dự báo nhiệt độ tối cao, hầu hết các hạn dự báo có độ lệch nhỏ (Bias<1) cho thấy các hạn dự báo đều dự báo nhiệt độ tối thấp thấp hơn giá trị quan trắc. Hạn dự báo $3,4,5$, và 6 ngày có độ lệch Bias $\approx 1$ phản ánh chất lượng dự báo tốt, độ lệch dự báo tốt nhất tại hạn dự báo 3 ngày $(B i a s=0,99)$. Độ lệnh tại các hạn dự báo $7,8,9$ và 10 cho thấy sai số dự báo lớn nhất.

- Chỉ số ME nhận giá trị từ - 0,22 đến $-0,94$ (hình $15 b$ ), phản ánh giá trị dự báo nhiệt độ tối thấp trong tất cả các hạn dự báo đều thấp hơn giá trị thực đo. Hạn dự báo $3,4,5$ và 6 ngày có sai số trung bình nhỏ nhất, sai số lớn nhất thuộc về hạn dự báo $7,8,9$ và 10 ngày tương đồng với kết quả phân tích chỉ số Bias ở trên.

- Chỉ số MAE nhận giá trị từ 1,02 đến 1,66 (hình 15c), có xu thế tăng dần theo các hạn dự báo, hạn càng dài sai số càng lớn đúng với quy luật chung.

- Chỉ số RMSE nhận giá trị từ 1,36 đến 3,42 (hình 15d), chỉ mức độ sai số trung bình của dự báo các giá trị sai số có xu thế tăng dần theo các hạn dự báo, hạn càng dài sai sổ càng lớn tương tự như biểu đồ chỉ số MAE.

- Chỉ số MSE nhận giá trị từ 1,86 đến 11,87 (hình 15e), chỉ mức độ sai số trung bình của dự báo các giá trị sai số có xu thế tăng dần theo các hạn dự báo, bản chất cũng giống như biểu đồ chỉ số RMSE và MAE.

- Chỉ số PC nhận giá trị từ 0,66 đến 0,93 (hình $15 f$ ), chất lượng dự báo tốt nhất tại các hạn dự báo 4,5 ngày $(\mathrm{PC}=0,93)$, thấp nhất đối với hạn dự báo 10 ngày $(\mathrm{PC}=0,66)$. 


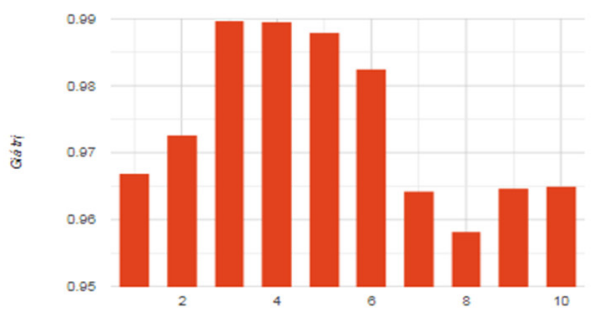

(a)
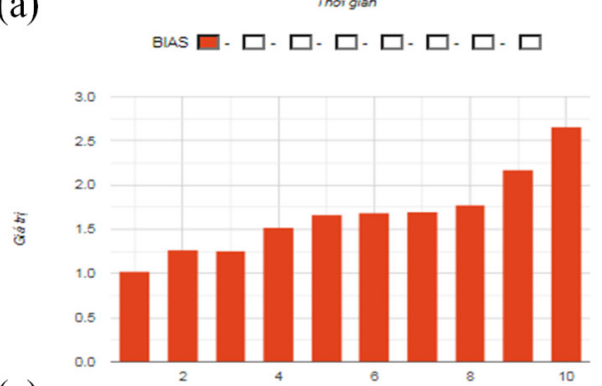

(c)

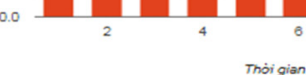

MAE $\square \cdot \square \cdot \square \cdot \square \cdot \square \cdot \square \cdot \square \cdot \square$

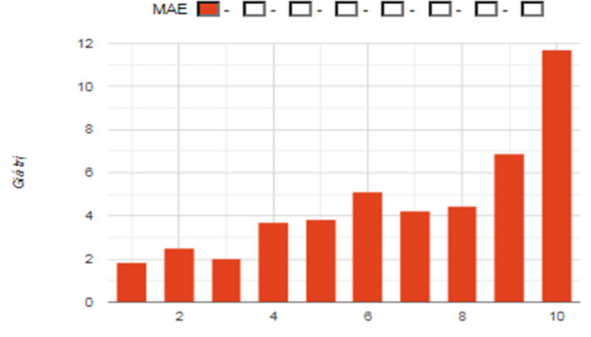

(e)

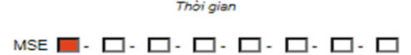

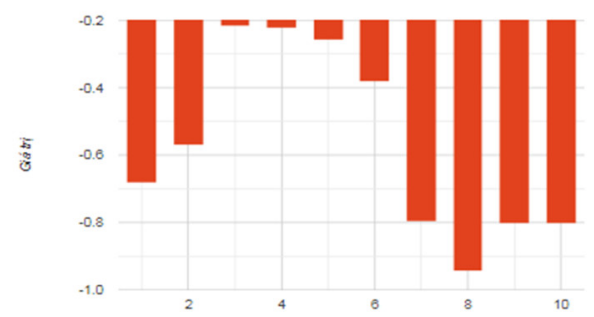

(b)
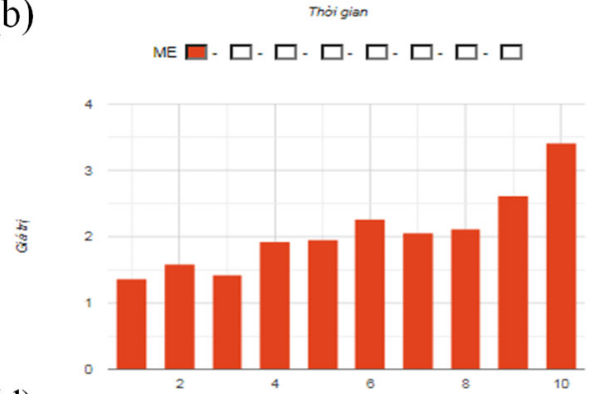

(d)

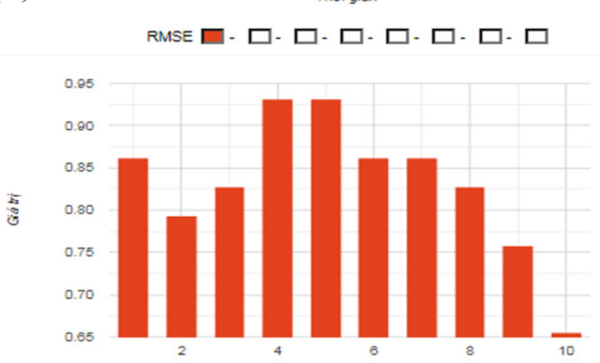

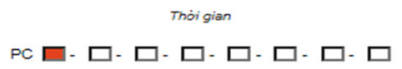

Hình 15. Chỉ số của các hạn dự báo: (a) Bias; (b) ME; (c) MAE; (d) RMSE; (e) MSE; (f) PC.

Để có thể xem kết quả chất lượng dự báo một các tổng quan nhất của tất cả các điểm dự báo, từ đó có thể so sánh, đánh giá chất lượng dự báo của điểm Hà Nội tháng 4 năm 2020 với tất cả các điểm dự báo khác (Hình 16), người dùng có thể lựa chọn Đơn vị dự báo, Yếu tố dự báo, Thời gian và Hạn dự báo sau đó kích vào nút Xem thông tin khi đó giao diện sẽ hiển thị các thông tin theo yêu cầu của người sử dụng tại trang chủ của hệ thống phần mềm.

Bản đồ phân bố chất lượng dự báo của từng yếu tố cho chúng ta biết chi tiết chất lượng của từng điểm dự báo cũng như tổng quan chung của tất cả các điểm dự báo từ đó cung cấp rất nhiều thông tin bổ ích cho nhà quản lý cũng như dự báo viên.

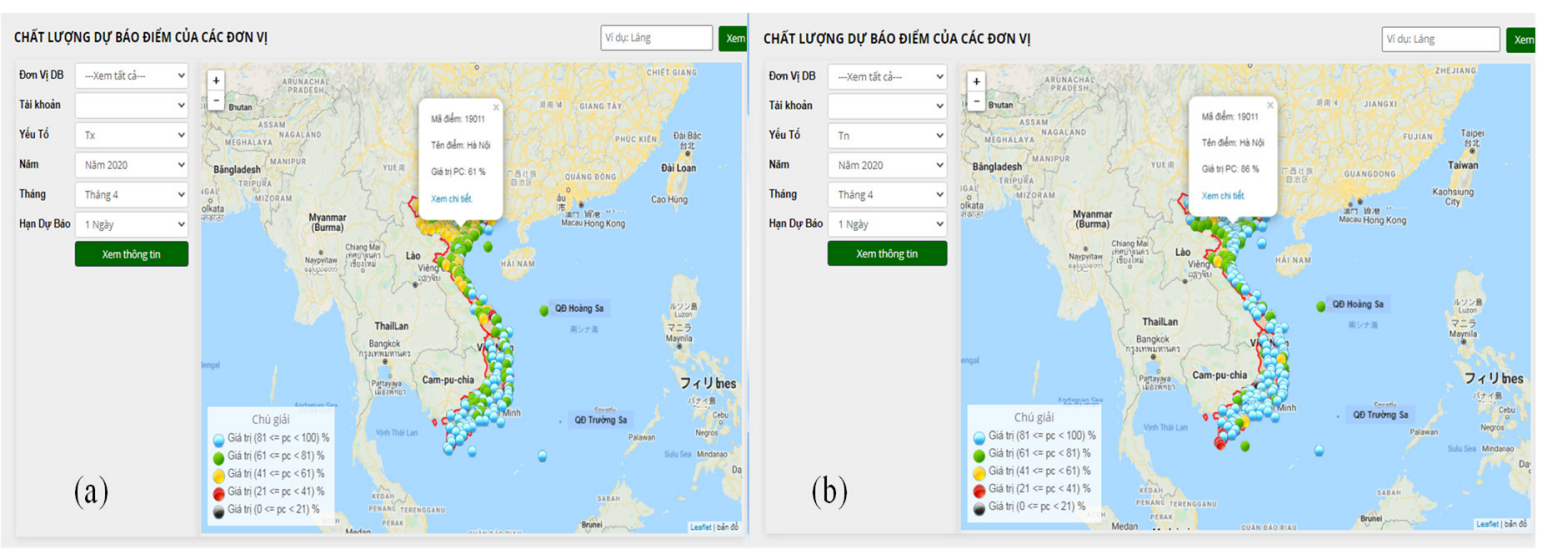

Hình 16. Chất lượng dự báo nhiệt độ cực trị điểm Hà Nội tháng 4 năm 2020: (a) Chất lượng dự báo Tx; (b) Chất lượng dự báo Tn. 


\section{Kết luận}

Phần mềm đánh giá chất lượng dự báo thời tiết điểm được xây dựng trên cơ sở lý thuyết của các nhà khoa học, hướng dẫn của $\mathrm{WMO}$ và quy định của Việt Nam [1,9]. Trong khuôn khổ nội dung bài viết này Tác giả đã lựa chọn yếu tố nhiệt độ cực trị ngày để trình bày một trong rất nhiều tính năng của phần mềm đánh giá chất lượng dự báo thời tiết điểm nhằm mục đích giới thiệu một phương pháp phổ biến dùng để đánh giá chất lượng dự báo cho điểm Hà Nội trong tháng 4 năm 2020 của yếu tố nhiệt độ cực trị bằng kỹ thuật toán đồ tụ điểm và Tính toán, phân tích các tham số sai số dự báo cho ta kết quả:

- Sai số dự báo nhiệt độ tối cao lớn hơn sai số dự báo nhiệt độ tối thấp;

- Giá trị nhiệt độ tối cao dự báo cao hơn giá trị quan trắc ở một vài hạn dự báo nhưng đa phần thường dự báo thấp hơn so với giá trị quan trắc, ngược lại đối với giá trị nhiệt độ tối thấp thường dự báo thấp hơn so với giá trị quan trắc;

- Chất lượng dự báo cả nhiệt độ tối cao và tối thấp đạt mức trung bình với hạn dự báo 1 ngày và giảm xuống tại hạn 2 ngày sau đó tăng lên và đạt chất lượng tốt nhất tại hạn dự báo 3 , 4 ngày rồi giảm dần xuống thấp nhất tại hạn dự báo 10 ngày.

Việc sử dụng kết hợp đồng thời hai kỹ thuật phân tích giúp cho việc đánh giá chất lượng dự báo được nhanh chóng và chính xác, sai số dự báo tính được của từng yếu tố dự báo là thước đo kiểm tra mức độ chính xác của giá trị dự báo và giá trị quan trắc thực tế, đảm bảo sản phẩm dự báo thời tiết cung cấp và đáp ứng được yêu cầu người sử dụng, đảm bảo tính hiệu quả của hệ thống cung cấp sản phẩm dự báo thời tiết, đảm bảo độ tin cậy và giá trị của cơ quan cung cấp sản phẩm dự báo thời tiết.

Kết quả của phần mềm đánh giá chất lượng dự báo yếu tố nhiệt độ cực trị cho điểm Hà Nội, trong tháng 4/2020 chưa phản ánh gì nhiều trong nội dung của bài toán đánh giá chất lượng dự báo, nhưng kết quả ban đầu này có thể hứa hẹn sẽ có thể cung cấp cho dự báo viên có thông tin để kịp thời hiệu chỉnh hệ thống dự báo, trong tương lai khi phần mềm này được chính thức đưa vào hoạt động nghiệp vụ trong khoảng thời gian đủ dài, với dữ liệu đủ lớn, khi đó kết tính toán các chỉ số sai số dự báo của phần mềm sẽ cung cấp nhiều thông tin hữu ích và đủ độ tin cây hơn giúp các nhà khoa học nghiên cứu, phân tích và phát triển sản phẩm dự báo mới đồng thời phục vụ các nhà quản lý hô̂ trợ ra quyết định chỉ đạo, điều hành chính xác và đạt hiệu quả cao.

Đóng góp của tác giả: Xây dựng ý tưởng nghiên cứu: LĐT, NVL; Lựa chọn phương pháp nghiên cứu: LĐT, NVL; Xử lý số liệu và tính toán: LĐT; Viết bản thảo bài báo: LĐT; Chỉnh sửa bài báo: NVL.

Lời cảm ơn: Nghiên cứu trên được thực hiện dưới sự tài trợ của đề tài nghiên cứu khoa học cấp Bộ TNMT, mã số: TMMT.2017.05.11. Vì vậy, trước tiên Chúng tôi xin gửi đến các chuyên gia khí tượng thủy văn cùng tập thể các cộng tác viên thực hiện đề tài: "Nghiên cưu xây dựng hệ thống tụ động đánh giá khách quan chất lương dư báo tại các điểm trên khu vực Việt Nam" lời cảm ơn chân thành, sâu sắc nhất. Đặc biệt, chúng tôi xin chân thành cảm ơn Lãnh đạo Tổng cục Khí tượng Thủy văn và các đơn vị chức năng đã tạo điều kiện thuận lợi để chúng tôi thực hiện và triển khai ứng dụng đề tài này.

Lời cam đoan: Tập thể tác giả cam đoan bài báo này là công trình nghiên cứu của tập thể tác giả, chưa được công bố ở đâu, không được sao chép từ những nghiên cứu trước đây; không có sự tranh chấp lợi ích trong nhóm tác giả.

\section{Tài liệu tham khảo}

1. Bộ Tài nguyên và Môi trường. Quy định kỹ thuật đánh giá chất lượng dự báo, cảnh báo khí tượng, Thông tư số 41/2017/TT-BTNMT, 2017. 
2. WMO, 7th International Verification Methods Workshop. Forecast Verification methods Across Time and Space Scales, 2017. Avaliable online: https://www.cawcr.gov.au/projects/verification/.

3. WMO No.1023. Guidelines on performance assessment of public weather services, Geneva, Switzerland, 2000.

4. Stanski, H.R.; Burrows Wilson, W.R. Survey of Common Verification Methods in Meteorology. World Weather Watch Technical Report 1989, 8, 9-42.

\title{
The results of the automatical software evaluate the point weather forecast quality of the daily extreme temperature factor
}

\author{
Le Dai Thang ${ }^{*}$, Nguyen Viet Lanh ${ }^{2}$ \\ ${ }^{1}$ HydroMeteorology Information and Data Center: ledaithang.73@gmail.com \\ ${ }^{2}$ HaNoi University of Natural Resources and Environment; nvlanh@hunre.edu.vn
}

\begin{abstract}
The weather forecast point in Vietnam, implementing the quality assessment problem for forecasting factors will be divided into two categories: phase variables (subgroups) and continuous variables, For each type of variables, it is required to calculate predictive error index and apply different analysis techniques. In the scope of this study, we use the standard method of evaluating predictive quality by a combination of two techniques of analyzing the convergence of the graph and parametric analysis, apply for daily extreme temperature (continuous variable) in April 2020 for Hanoi points by automated software. The research results show that the predictive error of the maximum temperature is greater than the predictive error of the minimum temperature and the extreme temperature value at the forecast limits is usually lower than the observed value. There are also many other very useful information about the quality of the forecast. The results of the forecast quality assessment system will help forecasters and managers to promptly adjust the forecast and have a plan to research, improve, and develop to improve the level of forecasting in the future.
\end{abstract}

Keywords: Forecasting points; Assessing quality forecast; Standard methods. 